\title{
Crianças E INFÂNCIAS NA CULTURA Visual: CONCEPÇÕES E NARRATIVAS FOTOETNOGRÁFICAS
}

\author{
Fernanda Mendes Cabral Coelho \& Adelaide Alves Dias
}

\begin{abstract}
RESUMO
Este artigo tem o objetivo de ressaltar a importância da cultura visual para a compreensão histórica e social das concepções de crianças e infâncias constituídas à luz dos pressupostos teóricos da sociologia da infância, bem como destacar o uso da narrativa fotoetnográfica para a compreensão da realidade em pesquisas científicas, mais especificamente relacionadas à Infância. Para tanto, apresenta três narrativas imagéticas produzidas a partir das imagens de crianças dispostas em pesquisas científicas no Brasil, pautadas nos pressupostos epistemológicos e empíricos da História e da sociologia da infância. Trata-se de um estudo qualitativo e descritivo, de estratégia fotoetnográfica, com uma análise produzida à luz de uma perspectiva crítica e transdisciplinar multireferencial. Através das narrativas fotoetnográficas, o estudo revelou que as infâncias se constituem na multiplicidade das sociedades humanas, em que cada época e contexto oferecem às crianças possibilidades de criação e apropriação cultural, desencadeando assim, novas e inusitadas formas de vida, onde as crianças criam para si estratégias de sobrevivência e resistência. Neste sentido, pensar o universo das culturas infantis na perspectiva da cultura visual requer um movimento constante de reflexão sobre como estes espaços refletem concepções e imagens de crianças e contribuem para a formação dessas culturas.
\end{abstract}

\section{Palavras-chave}

Crianças; cultura visual; fotoetnografia; infâncias; sociologia da infância

\begin{abstract}
This article highlights the importance of visual culture for the historical and social understanding of the conceptions of children and childhoods constituted in light of the theoretical assumptions of sociology of childhood, as well as, emphasizes the use of the photoetnographic narrative to understand reality in scientific researches, specifically related to childhood. For that, it presents three imaginary narratives produced from the images of children prepared in scientific research in Brazil, based on the epistemological and empirical presuppositions of History and sociology of childhood. It is a qualitative and descriptive study, of photoetnographic strategy, that includes an analysis produced in the light of a multireferential, critical and transdisciplinary, perspective. Through the photoetnographic narratives, the study revealed that childhood is constituted by the multiplicity of human societies, in which each age and context offer children possibilities for cultural creation and appropriation, thus triggering new and unusual forms of life, where children create for themselves strategies of survival and resistance. In this sense, thinking about the universe of children's cultures in the perspective of visual culture requires a constant movement of reflection on how these spaces reflect conceptions and images of children and contribute to the formation of these cultures.
\end{abstract}

\section{KEYWORDS}

Childhood; children; photoetnography; sociology of childhood; visual culture 


\section{INTRODUÇÃO}

A cultura visual permite representar os objetos de caráter mediacional de diferentes épocas e culturas, estimula interpretações sobre a realidade e sobre como estas afetam a vida dos indivíduos. Nessa perspectiva, o estudo da cultura visual tem como objeto as representações que os indivíduos constroem da realidade, segundo suas características sociais, culturais e históricas. Ou seja, é uma ciência que procura "compreender o que se representa para compreender as próprias representações" (Hernández, 2000, p. 136). Ressalta-se também que a cultura visual não depende das imagens em si mesmas, mas da busca e captura de reflexos da realidade, justamente por considerar a imagem como um lugar de criação e discussão de significados (Mirzoeff, 2003).

Partindo dessas premissas, este trabalho teve o objetivo de ressaltar a importância da cultura visual para a compreensão histórica e social das concepções de crianças e infâncias constituídas à luz dos pressupostos teóricos da sociologia da infância. Pretende destacar também o uso da narrativa fotoetnográfica para a compreensão da realidade em pesquisas científicas, mais especificamente relacionadas com a infância. Constituímos um recorte de uma tese de doutoramento, já em fase conclusiva, vinculada ao Programa de Pós-Graduação em Educação da Universidade Federal da Paraíba - Brasil. Para tanto, optamos por construir narrativas fotoetnográficas a partir das imagens de crianças dispostas em artefatos visuais como pinturas clássicas europeias e fotografias produzidas em diferentes épocas e contextos.

Metodologicamente, trata-se de uma pesquisa qualitativa descritiva e de um procedimento fotoetnográfico' (Achutti, 1997), bibliográfico e documental. A geração de dados (Graue \& Walsh, 2003) foi organizada em três contextos diferenciados e interligados: o primeiro refere-se às imagens de crianças na sociedade europeia cujos elementos discursivos influenciaram as primeiras construções conceptuais nas ciências humanas e sociais; o segundo revela a influência dos padrões europeus nas formas de ser e de viver da infância no Brasil, a partir de imagens de criança nas produções científicas na área da sociologia da infância; o terceiro contexto ressalta a reconfiguração conceptual de crianças e infâncias na sociedade contemporânea, a partir das culturas infantis projetadas na cultura visual moderna.

Para a seleção e sistematização iconográfica foram utilizados os seguintes critérios: imagens dispostas em estudos e pesquisas científicas que abordaram como objeto de investigação a criança e a infância; registros em pinturas clássicas da Idade Média que dialogam com as primeiras construções conceptuais de infância selecionadas nas pesquisas; imagens de crianças dispostas em mídias digitais como blogs e redes sociais. Entretanto, as imagens destacadas para esboçar o presente texto são seleções arbitrárias de nossos próprios olhares críticos, como professoras e pesquisadoras da infância, resultado de várias decisões prévias que dialogaram com os fundamentos teóricos e práticos da sociologia da infância.

\footnotetext{
' As narrativas fotoetnográficas estão dispostas mais à frente neste artigo, retratando as discussões apresentadas e se oferecendo a outros novos olhares.
} 
As análises foram organizadas a partir do diálogo interdisciplinar entre as fontes selecionadas, o rigor interpretativo transdisciplinar multireferencial (Sardelich, 2006) entre as contribuições da História, da sociologia da infância e da perspectiva crítica da cultura visual. Todavia, não intencionamos estabelecer recortes temporais tendo em vista que o movimento de seleção de imagens partiu das teorizações investigadas e não das iconografias em si. Deste modo, as imagens emergem à medida que surgem os conceitos. Logo se estabelece uma relação de sentido nas imagens do passado versus do presente (agora produzidas através de novos artefatos culturais), mas que não é alheio à realidade da criança de cada geração.

Dado o exposto, o texto inicialmente ressalta a importância da cultura visual para a produção de estudos e pesquisas com/sobre crianças, em diálogo com os pressupostos da fotoetnografia como perspectiva teórico-metodológica para constituições de narrativas imagéticas. Em seguida, destaca as concepções de crianças e infâncias à luz da sociologia da infância, em interlocução com elementos históricos e culturais de épocas e contextos diferenciados. Por fim, apresenta as narrativas fotoetnográficas, reflexionando sobre as diferenças entre como eram e são representadas as crianças através da cultura visual e como essas representações repercutem nas interpretações e (in)formações acerca das culturas infantis de cada época.

\section{CULTURA VISUAL E FOTOETNOGRAFIA: NOVOS OLHARES TEÓRICO-METODOLÓGICOS PARA PESQUISAS SOBRE CRIANÇAS E INFÂNCIAS}

Os estudos atuais da cultura visual partem da confluência de diferentes disciplinas, desde a Sociologia, a Antropologia, a Semiótica, os Estudos Culturais e Feministas e a História Cultural da Arte, sob diferentes perspectivas teórico-metodológicas que problematizam e contextualizam os fenômenos que perpassam a vida cotidiana e suas visualidades (Hernández, 2000). Desse modo, a cultura visual compreende a interface entre todas as disciplinas que lidam com a visualidade no contemporâneo (Mirzoeff, 2003).

Para a abordagem dos fenômenos visuais pelo viés da cultura visual e suas implicações para a compreensão da vida cotidiana, torna-se necessário reflexionar os conceitos de cultura e visual numa perspectiva crítica, inseridos num campo de estudos transdisciplinar multireferencial (Sardelich, 2006, p. 465) que "não se organiza a partir de nomes de artefatos, fatos e ou sujeitos, mas sim de seus significados culturais, vinculando-se à noção de mediação, de representações, valores e identidades".

Sardelich (2006) sugere que a compreensão crítica desses significados culturais implica considerar quatro aspectos não sequenciais e interconectados: histórico-antropológico; estético-artístico; biográfico e crítico-social. Em relação ao aspecto crítico-social, a autora ressalta a importância de estabelecer conexões entre as representações e artefatos visuais e suas significações, tendo em vista que são produzidos e legitimados no contexto das relações sociais tradicionais que envolvem costumes, crenças, ideias políticas e religiosas. Sobre o aspecto estético-artístico, a autora refere-se aos sistemas de representação compreendidos no cerne da cultura de origem da produção e não em 
sua universalidade. Quanto ao aspecto biográfico, ela defende que as representações e artefatos fomentam através dos processos identitários a construção de valores, crenças e visões sobre a realidade. E o aspecto crítico-social corresponde à contribuição das representações e artefatos visuais para a configuração atual das políticas da diferença e das relações de poder na sociedade.

A importância da imagem não está apenas no seu valor estético mas, sobretudo, no papel social que exerce na formação das culturas humanas (Martins, 2007; Mirzoeff, 2003). Portanto, os estudos da cultura visual problematizam a forma como os tipos de imagem perpassam a vida cotidiana constituindo e sendo constituída pelas experiências e complexidades das relações humanas. Então, não se trata de reconfigurar o objeto de estudo da cultura visual, mas de ampliar sua dimensão analítica na contemporaneidade, tendo em vista que "agora surge a necessidade de interpretar a globalização pós-moderna do visual como parte da vida cotidiana" (Mirzoeff, 2003, p. 19). Ou seja, é necessário passar a investigar como as experiências do cotidiano produzem, criam e disputam significados culturais que, direta ou indiretamente, exercem forte poder de verdade, "um poder intervencionista que acaba transformando o mundo imagético na própria vida" (Martins \& Tourinho, 2010, p. 138).

Nessa perspectiva, a tendência é considerar a imagem como reflexo da realidade, fonte histórica e narrativa de acontecimentos e experiências humanas, capaz de revelar significados e provocar sentimentos em quem registra, foi ou é registrado, e visualiza, foi ou é visualizado. Dessa forma, as imagens se tornam "fragmentos de comunicação, memória e marca identificatória" (Carvalho, 2011, p. 124). Portanto, através da imagem se solidificam emoções, histórias, narrativas e experiências que, para além de um signo, revelam intensas características e peculiaridades da realidade retratada.

Embora a sociologia da infância tenha contribuído, e ainda contribua, contínua e significativamente para a elucidação e problematização das causas relacionadas à criança, consideramos a cultura visual como um campo teórico indispensável para reflexionarmos as tensões, evoluções e reconfigurações conceptuais sobre infância(s) e culturas infantis, tendo em vista a forte influência das imagens para a compreensão e construção das narrativas que compõem a história das civilizações e, principalmente, considerando o patamar de importância que a imagem conquistou nas ciências sociais e humanas na atualidade (Achutti, 1997; Hernández, 2000; Mirzoeff, 2003; Sardelich, 2006).

Nesse diapasão, a fotoetnografia ${ }^{2}$ como vertente da antropologia visual, caracterizada como método de descrição e interpretação cultural que utiliza a fotografia como principal recurso narrativo, surge como uma importante estratégia para problematizar o objeto de estudo em questão.

Em termos de apresentação da fotoetnografia, Achutti (2004) sugere que as narrativas sejam compostas por uma sequência de imagens relacionadas entre si, sem nenhum texto intercalado. No entanto,

\footnotetext{
${ }^{2}$ O termo fotoetnografia foi cunhado por Luiz Eduardo Robinson Achutti, resultado da dissertação de Mestrado intitulada "Fotoetnografia: um estudo de Antropologia visual sobre cotidiano, lixo e trabalho" que objetivou compor uma narrativa fotográfica autônoma, apresentando o cotidiano de mulheres trabalhadoras da cidade de Porto Alegre que faziam reciclagem de lixo (Achutti, 1997).
} 
essa precaução não impede que certas informações escritas possam ter sido anteriormente dadas àqueles que vão mergulhar na narrativa visual, isto é, a justaposição dessas duas formas narrativas é possível e mesmo desejável, mas é importante notar que o ideal seria que cada tipo de escritura fosse oferecido ao leitor separadamente, de forma que cada uma conservasse todo o seu potencial. (Achutti, 2004, p. 109)

Deste modo, para a apresentação das fotoetnografias, organizamos quatro recortes fotoetnográficos posicionados na sequência do capítulo teórico correspondente ao contexto específico da narrativa. Devido à limitação física do texto, não foi possível empreender análises aprofundadas, e sim aproximações epistemológicas e dialógicas junto ao tema.

\section{A IMAgem da CRIANÇA NAS PRIMEIRAS CONSTRUÇões CONCEPTUAIS DE INFÂNCIA}

A iconografia da criança tem sido muito pesquisada recentemente no campo das ciências sociais. As contribuições de teóricos como Ariès (1981), Del Priore (1998), Kuhlmann Jr (1998), Sirota (2001), Sarmento (2007) e Qvortrup (2010), foram fundamentais para a compreensão da criança como sujeito social e da infância como estrutura geracional. Consequentemente, impulsionaram novas abordagens que culminaram no novo paradigma social da infância que rompe com as tradições culturais e históricas de (in) visibilidade e negação (Sarmento, 2007) e da ideia de criança como a projeção do adulto em miniatura (Ariès, 1981) ou como adulto em devir, tal qual considerada por Freinet (1994) ao afirmar que a natureza e os princípios que orientam a vida do adulto e da criança são os mesmos³.

Destes, destacam-se neste artigo dois autores indispensáveis para a construção de conceitos e concepções de criança, infância e culturas infantis: Philippe Ariès (1981), importante historiador francês, pioneiro nos estudos sobre criança e infância, descreve a evolução histórica desses conceitos em sua obra História social da criança e da família, sendo referência fundamental para a compreensão das transformações culturais vivenciadas por crianças em épocas medievais; e Manuel Jacinto Sarmento (2007), sociólogo português, precursor da nova sociologia da infância, que tem sido o grande interlocutor entre pesquisadores brasileiros e europeus.

Ariès (1981) dá ênfase à pintura realista da arte europeia para referenciar a representação da criança e designar a ausência do sentimento de infância, através da concepção histórica e cultural estabelecida sobre a criança. Destaca as obras de pintores famosos como: Rubens, Van Dyck, Franz Hals, Le Nain, Philippe de Champaigne e evidencia que "no mundo das fórmulas românicas, e até o fim do século XVIII, não existem crianças caracterizadas por uma expressão particular, e sim homens de tamanho reduzido" (Ariès, 1981, p. 51).

${ }^{3}$ Celéstin Freinet utiliza a metáfora hortícola para explicar a relação do educador com a criança. Para ele, a criança é como a árvore que cresce, se alimenta e se defende como a árvore adulta e o educador é um "bom jardineiro" que deve cuidar da planta para que ela possa florir e dar seus frutos à semelhança do adulto. No entanto, suas concepções foram bastante criticadas tendo em vista a ideia de criança como um mero receptor passivo (Araújo, 2002) 
De acordo com os registros de Ariès (1981), entre os séculos XIII e XVI, a criança foi representada a partir de uma forte iconografia religiosa, caracterizada pela tríade: imagem do "anjo adolescente" (aparência de um rapaz jovem para designar a criança); a imagem do "menino Jesus" (a infância aparece relacionada aos mistérios da maternidade), com um acento de ternura e ingenuidade, destacando-se que o menino Jesus nunca aparecia despido; E, após o século XIV, surge a imagem da "criança nua" ou o "putto", primeira referência na arte medieval da consciência da particularidade infantil. Até o século $\mathrm{XVI}$, as crianças eram raramente representadas e quando apareciam em pinturas e esculturas tinham uma musculatura adulta. Os artistas recusavam veemente a morfologia infantil.

Entre os séculos XIV, XV e XVI, quando a mortalidade infantil começou a preocupar a sociedade, as famílias burguesas começaram a considerar a criança em suas limitações e fragilidades, enquanto seres dependentes e fracos. Porém, essas famílias mantiveram as atribuições direcionadas à criança que desconsideravam as limitações do corpo infantil, levando-as a trabalhar nas mesmas condições dos adultos, sem tratamentos diferenciados na saúde, tampouco na convivência social em festas e até mesmo orgias (Ariès, 1981). Essa falta de atenção específica explica o alto índice de mortalidade da época, o chamado infanticídio; as famílias eram numerosas e não tinham muito apego às crianças, não existia o sentimento da infância, que para o autor correspondia à "consciência da particularidade infantil, essa particularidade que distingue essencialmente a criança do adulto, mesmo jovem" (Ariès, 1981, p. 156). No entanto, a inexistência do sentimento de infância não significava ausência de afeto às crianças pelos familiares.

Com a interferência dos poderes públicos e a preocupação da igreja em relação ao infanticídio, a proteção e o cuidado passou a ser a prioridade das mulheres, no caso, amas e parteiras, criando uma nova concepção sobre a manutenção da vida infantil, "como se a consciência comum só então descobrisse que a alma da criança também era imortal". Essa importância estava diretamente associada a uma cristianização mais profunda dos costumes (Ariès, 1981, p. 61).

As pinturas clássicas estavam presentes principalmente na vida das famílias burguesas que podiam subsidiar os artistas que durante dias produziam cenas da vida real (ver Figura 1).

A tela de Van Dyck representa os cinco filhos mais velhos do rei Carlos I (7 anos) da Inglaterra, no centro da tela o futuro herdeiro exibe uma solene veste vermelha sobressaindo-se dos demais. À esquerda Mary (6 anos) e James (4 anos), destaca-se que naquela época era comum meninos vestirem saias. As vestes refletem a falta de sensibilidade às especificidades da criança e reafirmam a ideia de adulto em miniatura, "a criança era, portanto, diferente do homem, mas apenas no tamanho e na força, enquanto as outras características permaneciam iguais" (Ariès, 1981, p. 14).

A pintura Infanta Margarida, produzida por Diego Velázquez (1659), o retratista oficial da corte espanhola em 1623, expressa a postura e as vestimentas usadas pela criança da realeza. Destacam-se o olhar tipo melancólico tentando minimizar as semeIhanças com os adultos, a falta de liberdade e a inexistência de características próprias 
da infância. O rosto pintado também revela a influência da cultura adulta na vida da criança como reprodução e semelhança.

No que se refere à imagem da criança em seus aspectos historicamente estabelecidos, Sarmento (2007) distingue duas etapas: a pré-sociológica e a sociológica. A imagem da criança pré-sociológica caracteriza-se por cinco concepções, que o autor define como imagens: criança má, criança inocente, criança imanente, criança naturalmente desenvolvida e criança inconsciente.
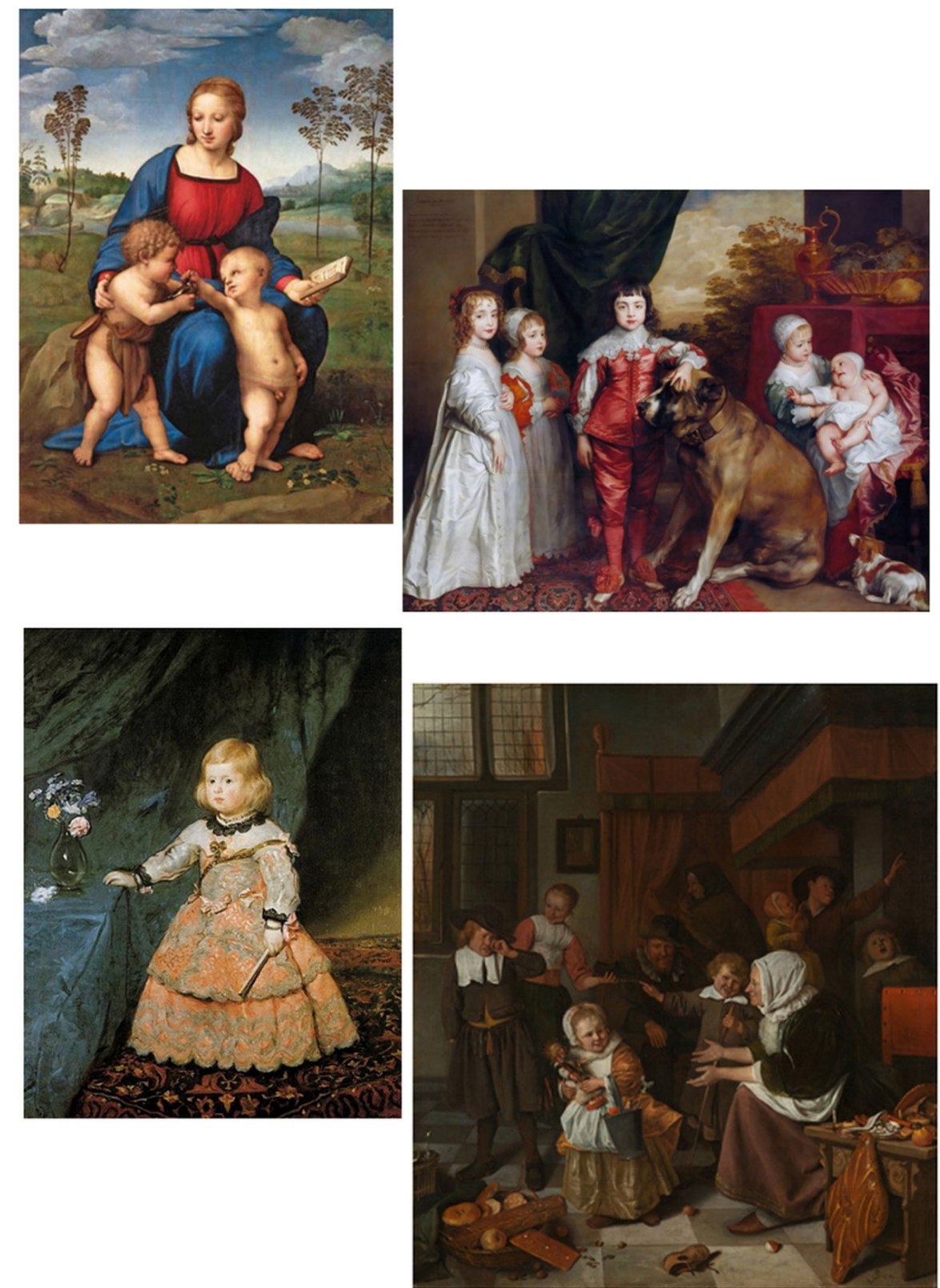

Figura 1: Fotoetnografia - Crianças e suas "infâncias" na cultura visual européia ${ }^{4}$

\footnotetext{
${ }^{4}$ Composto por: Tela de Raffaello Sanzio (1506), "Madonna do Pintassilgo", óleo no painel, 107x77cm (Galeria Uffizi, Florença); Tela de Anthony Van Dyck: "Los hijos mayores de Carlos I" (1637), 163 x 198 cm, óleo sobre lienzo (Ariès, 1981); Tela de Diego Velázquez (1653-1654), "A Infanta Margarida", $127 \mathrm{~cm}$ x $107 \mathrm{~cm}$, óleo em tela (Ariès, 1981); Tela de Jan Steen (1668), "A festa de São Nicolau", $82 \mathrm{~cm}$ x $70.5 \mathrm{~cm}$, óleo em tela (Ariès, 1981).
} 
A primeira imagem de criança pré-sociológica refere-se à criança concebida como uma expressão de forças indomadas, dionisíacas, com potencialidade permanente para o mal - criança má (the evil child), reforçando as intervenções paternalistas e a adoção de medidas de repressão infantil. Tal representação remete à imagem da Madonna do Goldfinch (1506) de Raffaello Sanzio que representa a figura feminina em momento devocional junto a duas crianças que estão interagindo entre si. Ao comparar a expressão facial das crianças é possível perceber em umas das crianças um olhar denso, quase perverso, diferente do olhar da outra criança que tem feições mais angelicais.

A partir do século XVII emerge outra concepção de criança marcada pelas transformações sociais, reformas religiosas e pela afeição no que se refere ao apego das famílias às crianças. Essas mudanças contribuíram para a consolidação do sentimento de infância e, consequentemente, deram início à preocupação com a higiene, a saúde física da criança, relacionada principalmente ao tratamento de doenças e à formação moral da criança, com forte tendência à religiosidade. Surge, portanto, o primeiro sentimento de infância, porém, de forma distorcida, com tendência ao que Ariès (1981) chamou de paparicação, ou seja, "a criança, por sua ingenuidade, gentileza e graça, se tornava uma fonte de distração e de relaxamento para o adulto" (p. 158).

Ariès (1981) o caracterizou como um "sentimento superficial", pois assim que as crianças cresciam, logo eram misturadas aos adultos e perdiam as regalias dos primeiros anos de vida. Não havia lugar específico para as crianças na sociedade, inexistia o sentimento de infância, tampouco se consideravam as crianças como um grupo social com características e necessidades próprias. Havia, sim, uma confusão de sentimentos em relação às crianças e suas infâncias, que variavam do cômico à irracionalidade, da distração à servidão, do cuidado à rígida disciplina.

O mito romântico da "paparicação" aponta para a segunda imagem da criança pré-sociológica - a da criança inocente, fundamentada na ideia da inocência, da pureza, da bondade e da beleza. Emílio de Rousseau (1995) embasa esta concepção ressaltando que a natureza do homem (quando nasce) é genuinamente boa e a sociedade a perverte. Sarmento (2007) ressalta que na obra "Emílio ou Da Educação", Rousseau destaca que a criança possui características específicas e particulares que exigem um tratamento diferenciado, tanto pela família quanto pelo processo de educação.

A forte tendência em dominar e moldar o comportamento infantil levava as crianças a se submeterem aos modelos dos adultos, tanto nas vestimentas quanto no comportamento. Essa tendência se materializava no cotidiano das famílias, onde se estabeleciam padrões de recompensa sobre o bom ou mau comportamento infantil como forma de dominar e controlar seus comportamentos (Ariès, 1981).

A tela de Jan Steen (1668) retrata a convivência social familiar durante uma celebração holandesa - a Festa de São Nicolau - Sinterklaas 5 (Ariès, 1981). A imagem compõe uma família numerosa reunida em meio à farta comilança. Podemos afirmar que o ponto

\footnotetext{
${ }_{5}$ Comemoração da chegada do São Nicolau. Conta-se a lenda que as crianças no dia o5 de novembro, véspera de São Nicolau, penduravam meias nas laterais das casas ou sapatinhos na janela e durante a madrugada ele enchia de doces e presentes os objetos das crianças que tinham se comportado bem o ano todo.
} 
central da imagem é a filha mais nova da família que acaba de ganhar uma recompensa de Saint Nicholas por ter se comportado durante todo o ano - uma boneca e guloseimas no balde. De modo contrário, seu irmão surge chorando por ter seu sapato vazio nas mãos da irmã, provavelmente por ter sido punido pelo seu mau comportamento.

A tela de Philippe de Champaigne (1649), que representa os sete filhos da família Habert (ver Figura 2), apresenta as crianças em cada idade trajando vestes de acordo com seu tamanho: o mais velho se veste como pequeno homem, ainda aparentando o mundo do adulto; os gêmeos à direita, de mãos dadas e ombros colados, exibem trajes idênticos, vestido comprido aberto na frente e fechado com botões e agulhetas - o vestido era usado culturalmente em meninos e meninas, o que revela ausência de gênero nas vestimentas. A partir do século VXII, a sociedade se preocupou em encontrar trajes adequados à condição da criança em cada idade (Ariès, 1981).
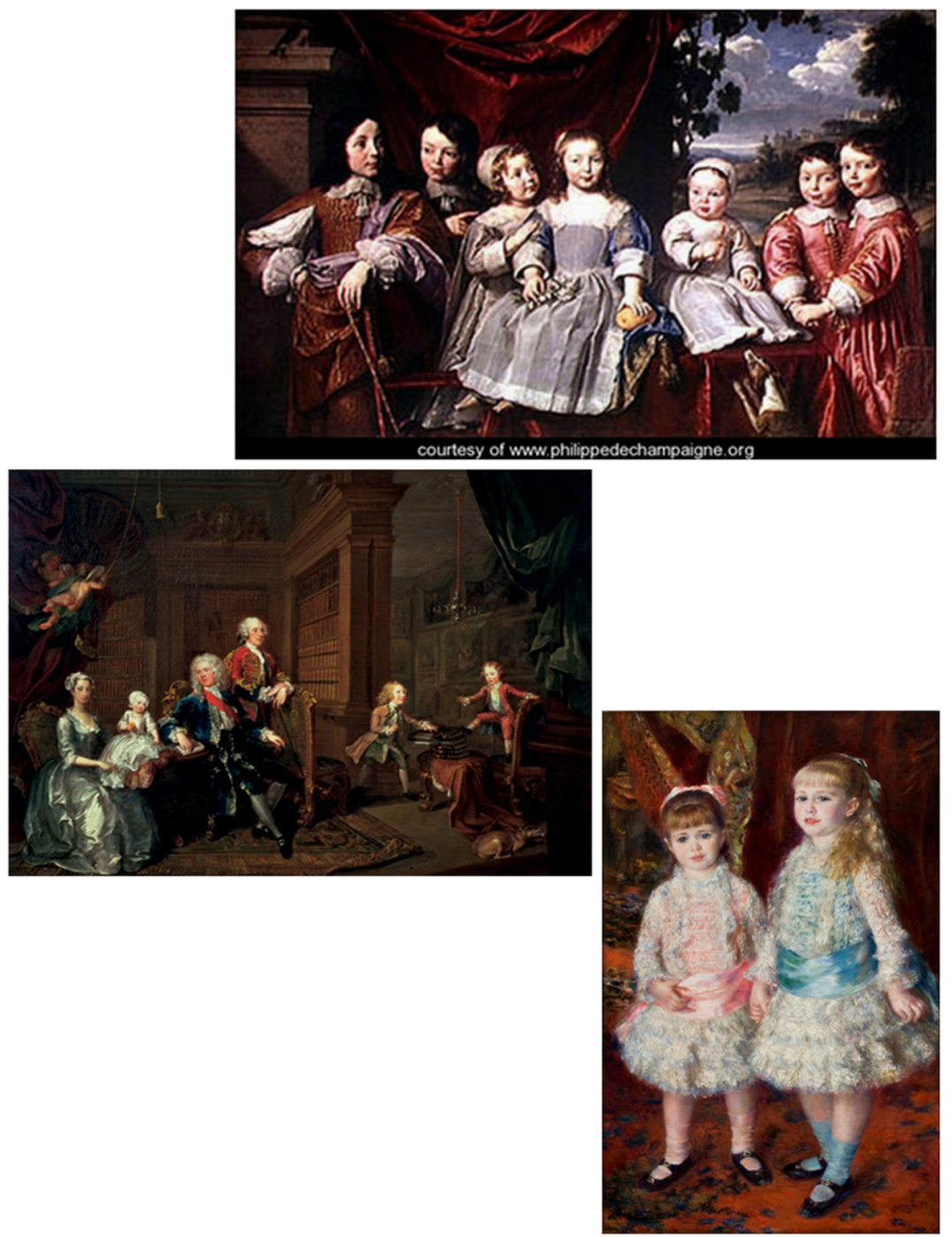

Figura 2: Fotoetnografia - Crianças e suas "infâncias" na Idade Média Européia ${ }^{6}$

\footnotetext{
${ }^{6}$ Mosaico composto por: Tela de Philippe de Champaigne (1649), "The Habert de Montmort Children", (Ariès, 1981); Tela de William Hogarth (1732), "The Cholmondely Family", 736 cm x 548, óleo em Tela (Ariès, 1981). Tela de Renoir (1881) "Alice e Elisabete Cahen d'Anvers". (1881). 119 x 74. Óleo sobre tela (Martins, 2013).
} 
Na imagem "The Cholmondely Family" de Hogarth (1732), é possível perceber a realidade de uma família nobre. A criança pequena teve maior destaque na iluminação dos tons e encontra-se ao lado de seus pais, ocupando lugar privilegiado na imagem. Também apresenta a essência da natureza infantil em crianças: surge brincando, mas sem nenhum objeto que remeta à própria criança. Isso reforça o tratamento igualitário entre adultos e crianças que desconsidera as características de cada fase. Mais uma vez, as imagens representam as crianças vestidas como adultos, mantendo a ideia da criança como "adulto em miniatura".

O século XVIII exprime com veemência a influência dos eclesiásticos na preparação moral da criança para a vida em sociedade. De acordo com os fundamentos da igreja, era preciso conhecer melhor a criança para poder corrigir os desvios e guiá-las para o caminho do bem (Ariès, 1981). Essa tendência pode ser compreendida a partir da terceira simbolização apontada por Sarmento (2007) sobre a criança pré-sociológica - a criança imanente, fundamentada na teoria da Tábula rasa de John Locke. A tendência era a crença que na criança poderiam ser inscritos quer o vício quer a virtude, a razão ou a desrazão, sendo missão da sociedade promover o crescimento com vista a uma ordem social coesa.

A partir do final do século XVIII, percebemos que as especificidades da criança vão sendo mais ressaltadas na arte, refletindo a mudança cultural acerca da condição infantil. Assim, a criança começa a apresentar marcas das transformações culturais que diferenciam crianças e adultos, desde as posturas até as vestimentas. A pintura nesse período dá cores e formas mais delicadas aos traços da criança, diferenciando-as dos adultos em aspectos como vestuário, expressão facial e adereços no cabelo, no caso das meninas, como encontramos na obra "As meninas Cahen d'Anvers", mais conhecida como Rosa e Azul, de Pierre Auguste Renoir (1881), pintor impressionista francês, que buscou retratar as irmãs Alice e Elisabeth, filhas do banqueiro Judeu Louis Raphael Cahen d'Anvers.

A tela foi objeto de estudo na pesquisa de Martins (2013), "Rosa e azul em terra verde-amarela: a trajetória do quadro de Renoir e sua presença no acervo do Museu de Arte de São Paulo (1881-1967)", na qual afirma que o quadro não representaria uma composição tradicional, mas sim uma forma moderna de retratos, ignorada pelo âmbito erudito, fugindo da proposta de legitimização da família Cahen d'Anvers como membros da alta burguesia Os trajes ganham cores e delicadeza nos tons pastéis, transmitindo o frescor e a inocência do sentimento de infância. A menina de azul tem em seu semblante um ar vaidoso e a de rosa aparentemente transmite certo desconforto. Esta imagem revela a ruptura cultural entre a representação das crianças como adultos em miniatura, diferenciando as crianças com vestes adequadas e utensílios que remetiam ao sentimento de infância.

Aline Silveira Becker, pesquisadora em artes visuais, discute as obras de Renoir em seu artigo "História e Imagens: a visualidade produzindo infâncias" e ressalta que a tela revela uma "uma infância bonita, delicada, mas também, introspectiva, passiva, comportada e devidamente amparada pela maternidade" (Becker, 2010, p. 96). A imagem 
corrobora com Heywood (2004) em seu livro "Umahistória da infância: da Idade Média à época contemporânea no Ocidente" ao afirmar que a infância passou por várias "descobertas". Porém, mesmo diante de relatos relativos à "inexistência do sentimento de infância" e à "adultização da criança", muitas crianças foram poupadas de traumas e viveram infâncias conforme suas condições de criança.

Portanto, a iconografia referente à infância na Idade Média limita as informações e demonstra, principalmente, a influência dos modos de vida adulta na vida da criança. Essa influência se materializa nas imagens que expressam comportamentos e sentimentos de uma "não infância". Cabe considerarmos que a infância retratada por Ariès tinha um tempo e um modo próprio daquele contexto e daquela cultura, não sendo aplicável, portanto, a todas as crianças de todos os contextos. As pesquisas brasileiras sempre partem dos pressupostos de Ariès para caracterizar suas bases teóricas, históricas e culturais. Deste modo, é visível a influência das concepções de criança europeias, narradas por Ariès, nas concepções de crianças e infâncias no Brasil. Essa influência pode ser percebida também na moda, nas relações familiares e nos comportamentos infantis que seguem os mesmos padrões adultizados de cultura.

\section{CRIANÇAS E INFÂNCIAS NO BRASIL: HISTÓRIA DE SUBMISSÃO OU RESISTÊNCIA?}

Com o intuito de representar as pluralidades das representações de crianças e infâncias contemporâneas, optamos por selecionar imagens que foram investigadas em pesquisas acadêmicas e científicas no Brasil. Esta foi uma tentativa de aproximação entre conceitos, imagens e representações. Buscamos reconhecer as nuances da modernização, em confronto com a tradição nos registros iconográficos de crianças que viveram e vivem as transformações econômicas, sociais, culturais da modernidade.

Em se tratando de imagem, o avanço tecnológico digital marcou a sociedade moderna provocando, consequentemente, mudanças significativas no campo da visualidade. Uma delas é que pintura artística perde popularidade para a fotografia. Este processo teve início no século XVIII com a criação da câmera escura. Porém, só se tornou popular com a criação da máquina fotográfica no século XIX e, em seguida, com a chegada da câmera digital e do smartphone com câmera acoplada e internet no século XX.

Esta simplificada explicação não é suficiente para demonstrar o impacto deste importante avanço, o que fugiria do objetivo do texto, mas serve para ressaltar que as transformações econômicas e tecnológicas ampliaram o acesso e o uso dos artefatos visuais: os artistas passaram a utilizar a imagem fotográfica como expressão da realidade, a fotografia passou a fazer parte do cotidiano social dos indivíduos de todas as idades e classes sociais (Martins \& Tourinho, 2010), as imagens se tornaram mais sofisticadas e acessíveis. Além disso, e principalmente, a imagem se popularizou, passou a fazer parte das rotinas da população e isso repercutiu também nas pesquisas científicas em todas as áreas do conhecimento.

Retomando a discussão sobre infância, as imagens presentes na iconografia da criança no século XIX demonstram que, apesar terem assegurado o chamado "sentimento 
de infância" (Ariés, 1981), ainda existe o rigor e a disciplina com forte impacto educativo, pois a infância passou a ser o momento oportuno para estabelecer regras, normas e formas de comportamento social. Nesse contexto, segundo Martins (2007), a escola passa a ter papel primordial na normatização da vida e das relações sociais, ou seja, o papel da escola seria o de preparar o menino e a menina para a vida.

Uma das primeiras constatações foi a de que as imagens deste período são construídas, orientadas e fundamentadas numa determinada visão de mundo e de cultura - a dos adultos, permanecendo assim, a tendência da concepção de crianças como "adultos em miniaturas" (Ariès, 1981). Entre o final do século XIX e início do século XX, os estudos das ciências da psicologia do desenvolvimento e aprendizagem, apesar de contribuírem em grande parte com os avanços científicos sobre cognição e desenvolvimento, relegaram à infância a mesma (in)visibilidade na qual as crianças mantém seu status de incapaz e de total dependência física, mental e social, portanto, "vulneráveis e requerendo ser moldadas, controladas e orientadas rumo a uma fase adulta desejável" (Lee, 2010, p. 46). Esta (in) visibilidade, presente no estudo da infância no campo das ciências sociais, marcado severamente pelo silêncio das crianças, compõe o cenário de duas últimas imagens pré-sociológicas: da criança naturalmente desenvolvida e a da criança inconsciente (Sarmento, 2007).

Em se tratando da imagem da criança naturalmente desenvolvida, há duas ideias centrais em torno desta imagem: a primeira em que as crianças são seres naturais, antes de serem seres sociais; e, a segunda, que a natureza infantil sofre um processo de maturação que se desenvolve por estágios. Ambas são fundamentadas principalmente nas contribuições da psicologia do desenvolvimento de Jean Piaget (1978).

Em relação à imagem da criança inconsciente, a criança é vista como um -'homúnculo' - preditor do adulto (Sarmento, 2007), pautado na Psicanálise, onde Freud é a maior referência. Esta imagem social imputa ao inconsciente o desenvolvimento do comportamento humano, com incidência no conflito relacional na idade infantil, especialmente na relação com às figuras materna e paterna.

A fotografia do acervo da antropóloga Gilda de Castro Rodrigues (ver Figura 3) dá as primeiras impressões sobre a realidade da infância do século XIX no Brasil: apresenta a imagem de um menino e uma menina com posturas eretas e expressões faciais sisudas, as roupas continuam reproduzindo o padrão adulto que perdurou ao longo dos séculos. É possível perceber que o olhar e as feições demonstram um certo grau de melancolia, nela, de tristeza, nele de uma superioridade também triste. Ficamos a nos perguntar: que tipo de infância está por trás desses rostos? De que maneira essas crianças conseguiam resistir aos padrões sociais impostos pela cultura adulta?

A pesquisa realizada por Kern et al. (2010) analisa a história da indumentária infantil no século XX, por meio de fotografias infantis publicadas na Revista Globo, a qual era editada na cidade de Porto Alegre/RS. O recorte cronológico utilizado pelos pesquisadores foi de 1929 a 1967. Os resultados apontam que a roupa da criança era diferente da roupa do adulto; modelos típicos de crianças como vestidos curtos, calças curtas, grandes laços na cabeça, sapato boneca, blusas de frio, casaquinhos eram bem utilizados 
e, para compor o visual, vestiam shorts e sapatos sociais com meias até a metade do tornozelo.
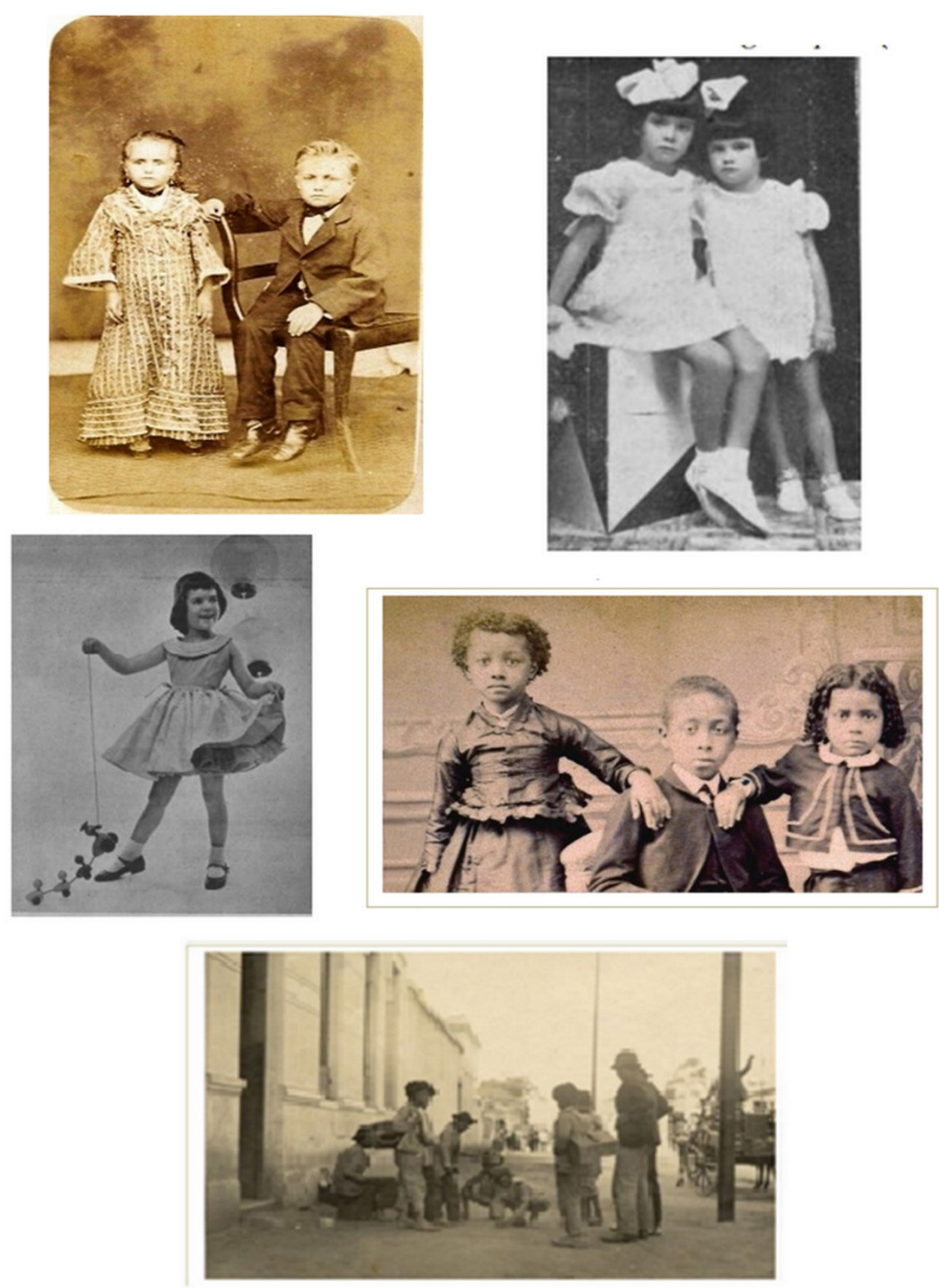

Figura 3: Fotoetnografia - Crianças e suas "infâncias" no Brasil”

A pesquisa intitulada: "Imagens de crianças e infâncias: a criança na iconografia brasileira dos séculos XIX e XX" de Abramowicz et al. (2011), evidencia a maneira pela qual a criança e sua infância foram retratadas durante esse período, com foco especial na representação da criança negra. Essa pesquisa indicou uma ambiguidade neste período: de um lado, a existência de um sentimento de infância e, do outro, a (in)visibilidade

\footnotetext{
7 Mosaico composto por fotografias: "Crianças século XIX, Santo Antônio do Monte" (s.d.), acervo Gilda de Castro Rodrigues (C); "Indumentária infantil século XX", Revista do Globo, 19 agosto de 1955 (citado em Kern et al., 2010); "Crianças no caminho para o trabalho" (s.d.), Militão Augusto de Azevedo, Museu Paulista, USP (citado em Abramowicz, et al., 2011).
} 
da criança e da infância, em especial da criança negra (p. 286). A fotografia de Militão Augusto de Azevedo, exposta no Museu Paulistano e discutida por Abramowicz et al. (2011), mostra três crianças negras, com olhar firme, vestes adultizadas, com marcas delimitadas de gênero, o que também é observado nas posturas e na posição em que cada um ocupa na imagem (ver Figura 3). Embora essa não seja nossa discussão, consideramos importante tencionar essa (in)visibilidade nos dias atuais, refletindo sobre a imagem de crianças negras representadas nas culturas visuais contemporâneas.

Outro achado desta pesquisa revela que as representações acerca das crianças que foram retratadas nos séculos XIX e XX geralmente são marcadas pelo conformismo do comportamento infantil, com a intenção de "configurar o caráter dos meninos para desde cedo moldar e formar o bom cidadão trabalhador e para as meninas a boa mãe e dona de casa" (Abramowicz et al., 2011, p. 281).

Quanto às fotografias referentes à infância no início do século XIX, importa relembrar que se trata de um período de intensos acontecimentos, desde guerras e revoluções, crises econômicas, avanços científicos e tecnológicos. Nesse contexto, as pessoas tiveram de se adaptar às diferentes realidades, principalmente relacionadas ao mundo do trabalho: com o avanço da tecnologia de produção nas fábricas, o emprego da força muscular masculina foi substituído pela mão de obra barata de mulheres e crianças:

a industrialização foi uma inimiga constante e terrível da infância. Com o crescimento da indústria e a necessidade de trabalhadores nas fábricas e nas minas, a natureza especial das crianças foi subordinada à sua utilidade como fonte de mão-de-obra barata (...) um dos efeitos do capitalismo industrial foi dar apoio aos aspectos penais e disciplinares da escola, que eram vistos como um sistema para dobrar a vontade da criança e condicioná-la ao trabalho rotineiro nas fábricas. (Postman, 1999, p. 67)

As crianças retratadas por Vincenzo Pastore $(1910)^{8}$, em exposição no Instituto Moreira Salles em São Paulo, apresentam pequenos trabalhadores, pobres e negros, alguns estão de pés descalços, outros com os uniformes de trabalho. A imagem indica movimento e o ambiente é a rua. Diante da imagem, podemos verificar que num universo marcado pelas culturas adultas, a criança vai tentando resistir através de suas fantasias e criatividades, transformando a hostilidade do trabalho em brincadeira de bola de gude na rua.

\section{AS CRIANÇAS NA CONTEMPORANEIDADE: NOVAS IMAGENS EM VELHAS IDEIAS}

Dos "sem-fala" à "ciberinfância" 9 , a construção conceitual de infância vem passando por inúmeras transformações onde a matriz principal de inteligibilidade tem sido

\footnotetext{
${ }^{8}$ Retirado de http://www.ims.com.br/ims/explore/artista/vincenzo-pastore

9 Termo cunhado por Dornelles (2005) que corresponde à infância online, conectadas à esfera digital, que utilizam computadores, internet, games, controles-remoto, joysticks, ou seja, a infância pós-moderna - da multimídia e das novas tecnologias da informação e comunicação.
} 
a cultura em toda sua complexidade e multiplicidade. O período da criança sociológica constitui-se pelas produções contemporâneas e resulta de um juízo interpretativo das crianças a partir das propostas teóricas das ciências sociais. São, de fato, processos de reinterpretação das representações anteriormente formuladas, com revisão do seu fundamento, pela compreensão simultânea da infância como "uma categoria social do tipo geracional e um grupo social de sujeitos ativos, que interpretam e agem no mundo. Nessa ação estruturam e estabelecem padrões culturais" (Sarmento, 2007, p. 36).

De acordo com Del Priore (1999), considerando a realidade da infância descrita pelas organizações brasileiras e internacionais, "o mundo no qual a 'criança deveria ser' ou 'ter' é rente daquele onde ela vive, ou no mais das vezes sobrevive" (Del Priori, 1999, p. 8). As crianças continuam a reproduzir culturas sociais adultas e, o que é pior, os próprios adultos estão convivendo com este retrocesso sem perceberem as graves consequências que isso pode gerar na vida da criança; pelo contrário, há uma total permissividade em relação às práticas de reprodução.

Isso caracteriza um retrocesso ao século XVII, considerando o que Ariès (1981) apontou sobre a condição da criança e o sentimento de infância nas sociedades medievais. As marcas da adultização infantil que consideram a criança como um adulto em miniatura (Ariès, 1981) ainda estão bem presentes nas relações sociais humanas em pleno século XXI, o que caracteriza uma falta de respeito à criança, suas especificidades e limites.

Recentemente, uma matéria sobre moda publicada pela Revista Caras on-line, reuniu imagens de crianças de várias partes do mundo, sob a intenção de mostrar as "6o crianças fofas mais estilosas do mundo"10. As roupas e acessórios para criança chamam atenção pelo fato de demonstrar uma ideia adultizada de infância, o que pode ser verificado no que o site chama de tendência atual da moda, de acordo com outro famoso site intitulado de fashionkids. Trata-se, portanto, de uma reprodução em potencial das culturas adultas na imagem de criança contemporânea. Mas, o que de fato revelam essas imagens? Que tipo de concepção de criança e infância essa matéria quis passar através do que denominam de "fashion kids"?

As imagens deste site (ver Figura 4) revelam um visual black com cores pouco variadas, as crianças usam penteados diferenciados e faixas no cabelo, vestem casacos estilosos, roupas sofisticadas, lenços, cachecóis e jeans casuais, algumas inclusive fazem referências a bandas de Rock e usam óculos de sol. As crianças exibem posturas com mãos nos bolsos, segurando acessórios como bolsas e mochilas. Esses elementos compõe a ideia de "mini-adultos", perde-se o colorido, a doçura e a brincadeira para dar lugar ao monocromático, à ousadia e à seriedade postural. As crianças modelam, fazem gestos e reproduzem cenas do cotidiano.

\footnotetext{
${ }^{10}$ No contexto do site, o termo "estilosa" significa estar vestido de acordo com as principais tendências da moda fashionkids. Retirado de http://www.fashionkids.nu/pb/
} 

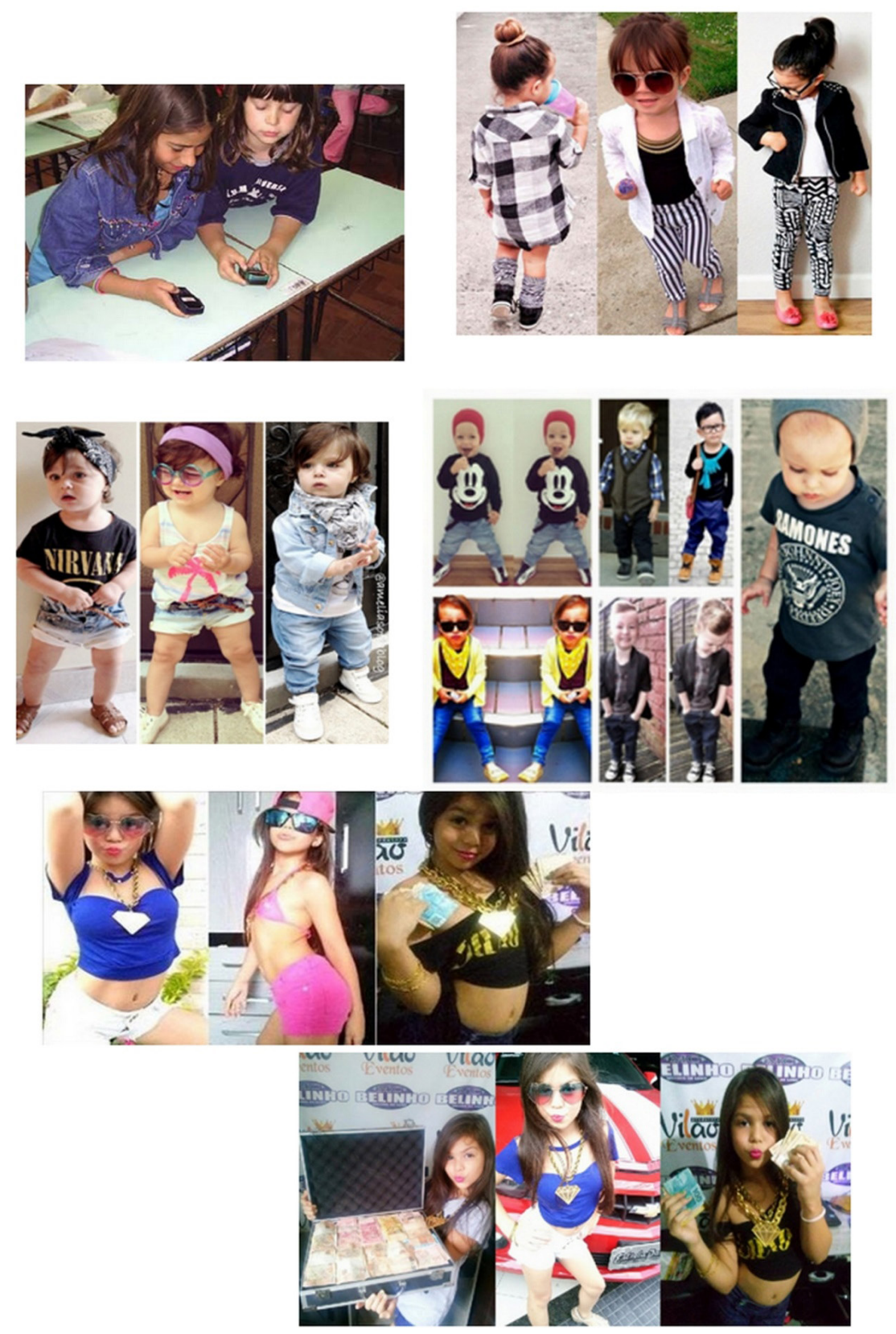

Figura 4: Fotoetnografia - As crianças e as infâncias no Brasil contemporâneo"

Mariângela Momo (2007), em sua tese de doutorado Mídia e Consumo de uma infância pós-moderna que vai à escola, ao tratar de infâncias contemporâneas e culturas midiáticas que envolvem a efemeridade das imagens e significados de criança, destaca que "a infância que vai à escola" leva consigo elementos da Cultura Visual, sobretudo midiática, e elabora suas próprias concepções de realidade, transgredindo padrões, e subvertendo aquilo que os adultos tendem a controlar e/ou conhecer. Nesta concepção, segundo a autora, o modo de ser criança na cultura contemporânea busca infatigavelmente a

\footnotetext{
"Mosaico composto por: "tecnológica (celulares)" (MOMO, 2007); “Fashion Kids" (2017), http://www.fashionkids.nu/ pb/; https://www.instagram.com/kardashiankids/; Mc Melody. (2016), extra.globo.com; diariodonordeste; verdesmares. com.br
} 
fruição e o prazer, procura incansavelmente inscrever-se na cultura globalizada, tornando-se consumidor de artefatos midiáticos, um processo que ultrapassa as fronteiras de classe, gênero e geração:

a produção, a circulação e o consumo de bens materiais e culturais se caracterizam pela aceleração e a provisoriedade, os ícones infantis apresentam a possibilidade de fruição, mas essa deve acontecer no momento presente, já que tais ícones são fugazes. Tal fruição envolve não apenas o deleite de bens materiais, mas também de bens culturais. (Momo, 2007, p. 69)

De acordo com Momo (2007, p. 297) "as crianças dos artefatos midiáticos preocupam-se com o estilo das roupas que vão vestir, usam com desenvoltura a internet, escolhem o que vão consumir e convencem as outras crianças de que aquele produto foi feito especialmente para elas". Tais condutas deixaram de ser apenas elementos das culturas adultas, fazendo parte do cotidiano de milhões de crianças independentes de classe, gênero, etnia.

Neste recorte reflexivo, retomamos alguns apontamentos que trazem visões contundentes sobre a condição da infância contemporânea. O exemplo de uma criança brasileira chamada Gabriella Abreu Severino, mais conhecida no mundo artístico como Mc Melody, é cantora de música pop e funk ostentação e já é notícia na televisão e na internet desde 2015. A partir de imagens retiradas de sites jornalísticos (ver Figura 4), é possível perceber que a criança exibe seu corpo de forma sensual e pejorativa, exibe dinheiro como troféu e apresenta expressões faciais que tentam esnobar quem a vê. Trata-se de uma criança, cantora de apenas 9 anos, que atualmente exerce forte influência na redes sociais.

Nitidamente as imagens demonstram um comportamento de adulto, com forte tendência abusiva. Em algumas fotografias, a criança expõe roupas sensuais, faz poses ousadas, usa sutiã com enchimento para valorizar os seios, exibe uma mala cheia de dinheiro e um colar de ouro. Sempre com maquiagens fortes, a cantora faz um "bico" com a boca para insinuar certo ar de deboche. Esse misto de narcisismo, consumismo e egocentrismo, também pode ser relacionado a uma padrão de beleza exaltado pela mídia e desejado pela maioria das pessoas que se exibem em redes sociais com a intenção de denotar "expressões de felicidade e completude". Essas pessoas buscam através de suas iconografias um estado permanente de beleza, de desejos voláteis consumistas e de superioridade egocêntrica, gerando assim o que chamo de cultura do exibicionismo e supervalorização da "autoimagem".

Inseridos num universo tecnológico e visual, as imagens se transformaram no produto mais essencial de nossa informação e conhecimento (Dias, 2005). Nesta perspectiva, o autor coloca que o aspecto da visualidade se refere,

ao nosso modo de olhar, ver, contemplar, fitar, mirar, observar, testemunhar, examinar, vislumbrar, olhar de relance, espiar, espreitar, e entrever o mundo, é particularmente relevante para a construção da representação 
do conhecimento e revela a necessidade de uma exploração adicional dos conceitos da comunicação e de representação cultural. (Dias, 2005, p. 282)

Portanto, a sociedade contemporânea apresenta à infância uma série de informações presentes na Cultura Visual que precisam de ser questionadas em sua complexidade, desde a dimensão política até seus impactos sociais na infância.

\section{CONSIDERAÇõeS FINAIS}

Reconhecemos que a imagem visual não é estável, mas muda sua relação com a realidade externa em determinados momentos da história e da cultura. Mais precisamente, a imagem torna-se um lugar onde se pode criar e discutir os significados. Nesta perspectiva, a cultura visual não depende da imagem em si, mas da tendência de interpretações que ela produz (Mirzoeff, 2003). Neste sentido, a cultura visual representada através das imagens selecionadas expressa signos e significados que contribuem para a mediação entre o processo de produção de conhecimento e a formação da consciência cultural de pertencimento histórico.

A relevância da imagem presente na pintura realista subsidia informações teóricas para pesquisas contemporâneas. Nesse sentido, a influência da cultura europeia nos primeiros registros iconográficos que expressam significados acerca de como viviam e eram representadas as crianças pela sociedade medieval, citadas tanto nos escritos de Ariès (1981), quanto nos registros da sociologia da infância, permitem esboçar nuances das culturas infantis de diferentes épocas que permitem afirmar que as culturas adultas exerciam e ainda exercem significativa influência nas formas de viver e ser criança na atualidade. Daí ser necessário promover debates e políticas públicas que garantam a efetiva proteção dos direitos da criança e o compromisso social de garantir a dignidade da infância em sua integralidade.

Com base na revisão de literatura, é possível afirmar que a imagem da criança na cultura visual foi adquirindo status de realidade e passou a significar fonte inesgotável e indispensável de informação no contexto científico, sobretudo para o desvelamento das culturas infantis, considerando suas significativas contribuições à sociologia da infância.

Verificamos também que a Fotoetnografia, como uma dinâmica teórico-metodológica, permite não só examinar as narrativas imagéticas que compõem os discursos e as teorias que fundamentaram e fundamentam os estudos e pesquisas científicas, como também amplia as possibilidades de investigação, tendo em vista seu potencial narrativo imagético para compreensão da realidade.

Em se tratando das concepções de crianças e infâncias na cultura visual, as fotoetnografias revelam que as representações imagéticas não se baseiam em idades biológicas e em papéis sociais, mas em elementos como: aparência física, modos de vestir e de se relacionar com a cultura e a sociedade. Neste sentido, ao comparar as várias infâncias retratadas, percebemos um retrocesso conceptual às visões de Áries (1981) sobre a condição da infância no século XVII quando a falta de tratamentos diferenciados entre adultos e crianças deu origem à concepção de crianças como adultos em miniatura, 
relegando à infância a condição de marginalidade social. Com isso, é possível afirmar que as marcas do "homúnculo" ainda estejam bem presentes nas culturas visuais do século XXI.

Em síntese, as narrativas fotoetnográficas de crianças, infâncias e culturas infantis revelam que, na pluralidade das sociedades humanas, cada época e contexto oferecem às crianças possibilidades de criação e apropriação cultural e essas possibilidades desencadeiam novas e inusitadas formas de vida, em que as crianças criam para si estratégias de sobrevivência e resistência. Consequentemente, as novas narrativas sobre crianças e infâncias devem reconhecer que a estrutura social da infância se constitui nas relações estabelecidas entre as diversas instâncias da sociedade, estando imersas em mudanças históricas e transformações sociais e culturais.

Estas estruturas repercutem diretamente na estrutura social da infância, mudando consideravelmente suas experiências com a realidade, especialmente em se tratando de cultura, pois à medida que se multiplicam as socializações humanas, as culturas se misturam e se confundem. Mesmo dando a devida importância para essa multiplicidade cultural, é preciso estar alerta quanto aos limites e diferenciações necessárias entre culturas adultas e infantis.

No entanto, é preciso reconhecer os limites desta análise, quando pensamos nas pluralidades da infância, nas infâncias pobres, nas crianças trabalhadoras, nas relações sociais estabelecidas entre elas e com os adultos, nas multiplicidades dos contextos familiares e educacionais e, sobretudo, quando reconhecemos que mesmo vivendo influências das culturas adultas, as crianças elaboram suas visões de mundo, são atores sociais (Sarmento, 2007; Sirota, 2001) e nas alteridades da infância subvertem e resistem à padrões e práticas que tentam condicionar o comportamento infantil.

Conclui-se que é preciso discutir as imagens de crianças e infâncias que circulam nas culturas visuais da sociedade contemporânea e conhecer o impacto dessas concepções para a formação das culturas infantis, bem como, partindo dessas realidades, analisar as relações que as crianças têm estabelecido com essas visualidades no cotidiano. Essas e outras questões nos inspiram a continuar pesquisando esta tão instigante temática.

\section{REFERÊNCIAS BIBLIOGRÁFICAS}

Abramowicz, A.; Silveira, D. B.; Jovino, I. S. \& Simião, L. F. (2011). Imagens de crianças e infâncias: a criança na iconografia brasileira dos séculos XIX e XX. Perspectiva, 29(1), 263-293.

Achutti, L. E. R. (1997). Fotoetnografia: um estudo de antropologia visual sobre cotidiano, lixo e trabalho. Porto Alegre: Tomo Editorial: Palmarinca.

Achutti, L. E. R. (2004). Fotoetnografia da Biblioteca Jardim. Porto Alegre: Editora da UFRGS/Tomo Editorial.

Araújo, A. (2002). Imagens de infância. Um estudo do imaginário educacional de Celestin Freinet. Comunicação e Sociedade, 4, 147-162.

Ariès, P. (1981). História social da criança e da família. Rio de Janeiro: Guanabara Koogan. 
Becker, A. S. (2010). História e imagens: a visualidade produzindo infâncias. In R. Martins; I. Tourinho (Ed.), Cultura Visual e Infância (vol. 1, pp. 89-104). Santa Maria: Editora UFSM.

Carlos, E. J. (2010). Introdução: por uma pedagogia crítica da visualidade. In C. E. João (Ed.), Por uma Pedagogia Crítica da Visualidade (pp. 11-25). João Pessoa: UFPB.

Carvalho, C. A. C. (2011). Os usos de fotografias de família. In C. Peixoto (Ed.), Antropologia e Imagem: Narrativas Diversas (vol.1). Rio de Janeiro: Ed. Garamond.

Del Priori, M. (Ed.) (1998). História da criança no Brasil. São Paulo: Contexto.

Dias, B. (2005). Entre arte/educação multicultural, cultura visual e teoria queer. In A. M. Barbosa, Arte/ Educação Contemporânea: Consonâncias Internacionais (pp. 277-291). São Paulo: Cortez.

Graue, M. E \& Walsh, D. J. (2003). A investigação etnográfica com crianças: teorias, métodos e ética. Lisboa: Fundação Calouste Gulbenkian.

Hernández, F. (2000). Cultura visual, mudança educativa e projeto de trabalho. Porto Alegre: Artmed.

Heywood, C. (2004). Uma história da infância: da idade média à época contemporânea no ocidente. Porto Alegre: Artmed.

Kern, M. T.; Schemes, C. \& Araújo, D. C. (2010). A moda infantil no século XX: Representações imagéticas na revista do globo. Diálogos, 14(2), 399-427.

Kuhlmann Jr. M. (1998). Infância e educação infantil: uma abordagem histórica. Porto Alegre: Mediação.

Lee, N. (2010). Vozes das crianças, tomada de decisão e mudança. In F. Müller (Ed.), Infância em Perspectiva: Políticas, Pesquisas e Instituições (pp. 42-64). São Paulo: Cortez.

Martins, R. (2007). A cultura visual e a construção social da arte, da imagem e das práticas do ver. In M. O. Oliveira (Ed.), Arte Educação e Cultura (pp. 10-40).Santa Maria: Editora UFSM.

Martins, R. \& Tourinho, I. (2010). Cultura visual e infância. Santa Maria: Editora UFSM.

Martins, T. A. (2013). Rosa e azul em terra verde-amarela: a trajetória do quadro de Renoir e sua presença no acervo do MASP (1881-1967). Monografia. Curitiba: UFPR.

Mirzoeff, N. (2003). Una introducción a la cultura visual. Barcelona: Editorial Paidós. Retirado de https:// bibliodarq.files.wordpress.com/2013/11/4c-mirzoeff-n-una-introduccic3b3n-a-la-cultura-visual-primeraparte.pdf

Momo, M. (2007). Mídia e consumo de uma infância pós-moderna que vai à escola. Tese de Doutorado, Universidade Federal do Rio Grande do Sul, Brasil.

Postman, N. (1999). O desaparecimento da infância. Rio de Janeiro: Grafhia Editorial.

Qvortrup, J. (2010). A infância enquanto categoria estrutural. Educação e Pesquisa, 36(2), 631-643.

Sardelich, M. E. (2006). Leitura de imagens, cultura visual e prática educativa. Cadernos de Pesquisa, 36(128), 451-472.

Sarmento, M. J. (2007). Culturas infantis e interculturalidade. L. Dornelles (Ed.), Produzindo Pedagogias Interculturais na Infância (pp. 19-40). Petrópolis, Rio de Janeiro: Vozes.

Sirota, R. (2001). Emergência de uma sociologia da infância: evolução do objeto e do olhar. Cadernos de Pesquisa, 112, 7-31. 


\section{NOTAS BIOGRÁFICAS}

Fernanda Mendes Cabral Coelho possui Mestrado em Educação pela Universidade Federal da Paraíba (2008) e especialização em Psicopedagogia pela FIP/PB (2003), Graduação em Pedagogia pela Universidade Federal da Paraíba (2001). Atualmente é aluna do Doutorado em Educação da UFPB/PPGE, Professora da Universidade Federal da Paraíba, Centro de Educação - Campus I. Tem experiência na área de Educação, com ênfase em Metodologia Científica, atuando principalmente nos seguintes temas: educação infantil, processos em ensino-aprendizagem, culturas infantis, ciberinfâncias, TIC e Direitos Humanos.

E-mail: fmcabralcoelho@gmail.com

Endereço: Rua Manoel Lopes da Silva, 136. José Américo. João Pessoa - Paraíba Brasil. Cep. 58073-586

Adelaide Alves Dias possui graduação em Psicologia pela Universidade Federal da Paraíba (1986), mestrado em Psicologia (Psicologia Social) pela Universidade Federal da Paraíba (1992), doutorado em Educação pela Universidade Federal Fluminense (2001) e pós-doutorado em Educação pela Universidade do Estado do Rio de Janeiro (2013-2015). Atualmente é professora e pesquisadora dos Programas de Pós-Graduação em Educação e Coordenadora do Programa de Pós-Graduação em Direitos Humanos, Cidadania e Políticas Públicas (Biênios 2014-2016 e 2016-2018), da Universidade Federal da Paraíba. Coordenou o Programa do PROCAD/CAPES NF 797/2010, é pesquisadora Associada do CIERS-Ed (Centro Internacional de Estudos em Representações Sociais e Subjetividade - Educação) e da Cátedra UNESCO de Profissionalização Docente. É membro do Núcleo de Cidadania e Direitos Humanos (NCDH), do Fórum Estadual de Educação da Paraíba (FEE-PB) e do Fórum de Educação Infantil da Paraíba (FEIPB). É coordenadora do Núcleo de Pesquisas e Estudos sobre a Criança (NUPEC). Tem experiência nas áreas de Educação e de Psicologia, com ênfase em Educação Infantil e Educação em Direitos Humanos, atuando principalmente nos seguintes temas: infâncias, educação infantil, autonomia, políticas públicas educacionais e educação em direitos humanos.

E-mail: Adelaide.ufpb@gmail.com

Endereço: Rua Manoel Lopes da Silva, 136. José Américo. João Pessoa - Paraíba Brasil. Cep. 58073-586

* Submetido: 15/03/2017

$*$ Aceite: 23/05/2017 